A influência das músicas, dos games e dos filmes no comportamento agressivo dos jovens

\title{
CATEGORIA: clínico
}

INSTITUIÇÃO: CENTRO UNIVERSITÁRIO SÃO CAMILO

\section{AUTORES:}

RIBEIRO, G. F. (Rua Domingos do Carmo Leite, Caieiras, São Paulo, Brasil; Tel: 5511 94225-6873; Email: gabrielfidelis.r@gmail.com) ${ }^{1}$

TOGNI, B. B. ${ }^{1}$

MONFERDINI, E. F. ${ }^{1}$

DE OLIVEIRA, G. T. ${ }^{1}$

TEIXEIRA, G. C. C. 1

DURI, G. L. ${ }^{1}$

\section{ORIENTADOR:}

ZANETTA, S. ${ }^{2}$

${ }^{1}$ Discente da Faculdade de Medicina do Centro universitário São Camilo

2 Docente da Faculdade de Medicina do Centro universitário São Camilo 
A influência das músicas, dos games e dos filmes no comportamento agressivo dos jovens

\section{CATEGORIA: clínico}

DESCRITORES: “Agressão", "Filmes cinematográficos”, "Músicas” e "Jogos de vídeo game" 


\section{Resumo}

METODOLOGIA: Os artigos selecionados para esta revisão foram obtidos na Biblioteca BVS (Biblioteca Virtual em Saúde) na qual a base de evidência é a LILACS (Literatura Latino-Americana e do Caribe em Ciências da Saúde) e PubMed/Medline (National Library of Medicine and National Institutes of Health). Foram analizados 430 artigos dos quais, após aplicação de filtros, foram selecionados 6. OBJETIVOS: O presente trabalho tem como objetivo verificar a influência das mídias no comportamento dos jovens. RESULTADOS: A influência foi analisada a partir de games, músicas e filmes. A experiência de jogo influencia a percepção e interpretação de situações de jogo, podendo envolver estados afetivos, estruturas cognitivas e scripts comportamentais. Esses fatores podem guiar o comportamento dos jogadores em situações futuras. Quanto a música, verificou-se que interfere tanto em comportamentos antissociais - de agressão e violência - quanto no comportamento pró-social. Já quanto aos filmes, um experimento realizado por Gomide (2000) descreve uma pesquisa que avaliava os efeitos de filmes com cenas de violência sobre o comportamento agressivo de crianças, neste experimento, a autora concluiu que: no sexo masculino, os filmes com cenas de violência, aumentaram o comportamento agressivo, o que não ocorreu com o sexo feminino. O comportamento agressivo de meninas é afetado quando relacionado a cenas de violência que envolvem abuso psicológico e/ou sexual contra mulheres. CONCLUSÃO: Pode-se notar que jogos eletrônicos, música e cinema exercem significativa interferência no comportamento de seus interlocutores, na medida que fomenta indiretamente um comportamento de atitudes agressivas, na medida que eleva a realidade virtual para mais próximo do interlocutor e ativa áreas cerebrais que estão associadas ao prazer e recompensa. Ainda assim, os resultados necessitam de mais estudos para que se possa dar um veredito definitivo acerca dessa relação. 
A influência das músicas, dos games e dos filmes no comportamento agressivo dos jovens

\section{Resumo}

A presente revisão tem como objetivo verificar a influência das mídias (games, filmes e música) no comportamento agressivo dos jovens. É um estudo de abordagem qualitativa e quantitativa. Foram utilizadas como metodologia as bases de dados online BVS (Biblioteca Virtual em Saúde) na qual a base de evidência é a LILACS (Literatura Latino-Americana e do Caribe em Ciências da Saúde) e PubMed/Medline (National Library of Medicine and National Institutes of Health), com foco no público jovem. $\mathrm{O}$ presente trabalho teve como principal objetivo conhecer as influências das mídias nos aspectos psicológicos durante o desenvolvimento cognitivo. Vale apontar que existem diversos tipos de mídias influenciadoras, mas as principais foram abordadas nesta revisão bibliográfica.

\section{Metodologia}

Trata-se de uma revisão de literatura, nos moldes da revisão integrativa, com produções que utilizaram abordagem qualitativa em estudos na temática da influência das mídias de entretenimento, com enfoque nos jogos digitais, cinema e música e sua relação com o desenvolvimento de comportamentos agressivos em adolescentes.

Os artigos selecionados para esta revisão foram obtidos na Biblioteca BVS (Biblioteca Virtual em Saúde) na qual a base de evidência é a LILACS (Literatura LatinoAmericana e do Caribe em Ciências da Saúde) e PubMed/Medline (National Library of Medicine and National Institutes of Health).

Os critérios usados para a seleção de tais artigos foram: 1) a utilização dos seguintes descritores: agressividade AND games, agressividade AND cinema, agressividade AND música. Dessa primeira busca, foram totalizados 430 artigos. 2) Aplicação dos seguintes filtros: textos disponíveis, idioma (português e inglês), base de dados (LILACS,PUBMED/MEDLINE). A partir desta segunda busca foram excluídos 401 artigos, restando, desta forma, 29 artigos. 3) Seleção baseada por títulos e resumos que, por sua vez, excluiu 23 artigos. Portanto, fazem parte da presente revisão bibliográfica 6 artigos, conforme mostra o fluxograma abaixo. 


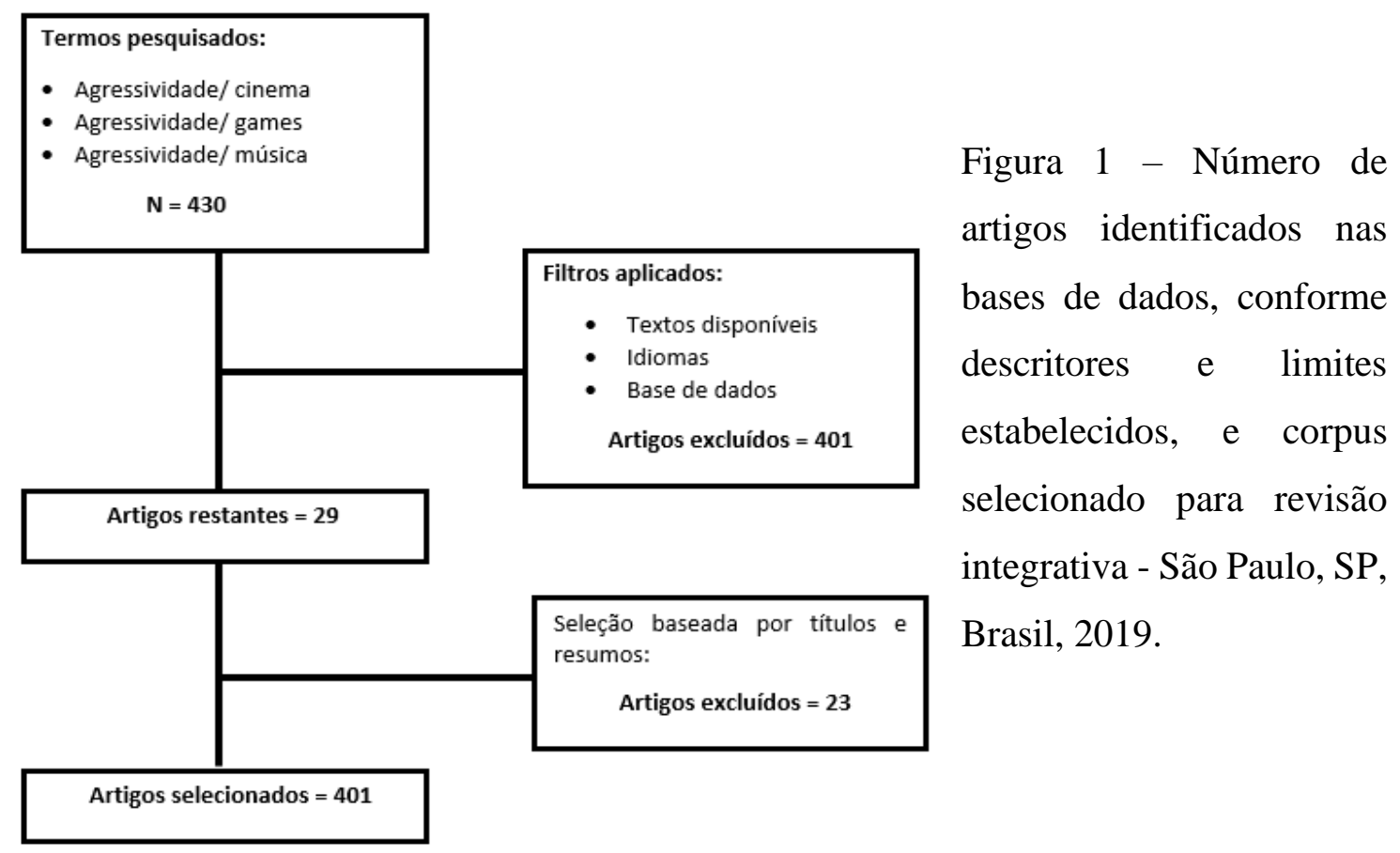

\section{Introdução}

Com a chegada do novo milênio, as dinâmicas culturais e sociais da sociedade se modificaram. Com a popularização de aparelhos de televisão e o nascimento das culturas tech e pop, a forma do indivíduo se divertir mudou consideravelmente. Em especial, com a popularização do cinema, com o advento de novos gêneros musicais e de novas tecnologias, como os jogos eletrônicos, foram fatos marcantes para mudar o entretenimento global como um todo.

Essas novas formas de entretenimento, alteram a percepção e interpretação da realidade pelos interlocutores e, dessa maneira, influenciam consideravelmente na mudança da realidade de seus usuários ${ }^{1}$. Até mesmo ouvir música, a atividade mais frequentemente realizada das citadas, pode ter influências em áreas neurais do cérebro e, consequentemente, no comportamento social do usuário ${ }^{2}$.

Em vista do debate do tema, em especial devido ao Massacre de Suzano e o trágico e marcante de Columbine, as mídias de entretenimento, como filmes, jogos e músicas, são tidas, muitas vezes, como fatores determinantes para os criminosos agirem. Assim, a discussão acerca do tema sempre retorna, o que abre espaço para esclarecimentos e levantamento de novos questionamentos. 
Os jogos vêm sendo apontados como grandes vilões do comportamento agressivo de jovens que chegam a passar horas entretidos na frente das telas. Alguns estudos correlacionam os jogos e a recompensa por eles criada quando o jogador promove algum ato violento, podendo ser transmitido esse condicionamento para a vida real. Porém, alguns estudos não permitem associar os jogos violentos e a característica agressiva de jovens sendo criticada a metodologia aplicada em ambos pontos de vista ${ }^{3}$.

Por outro lado, os filmes, que além de trazerem temas como sexo, drogas, suborno e prostituição muito cedo para as crianças, também tiram um pouco do tempo de convívio familiar. Nos estudos de Gomide (2000), fica evidente que esse tempo assistindo filmes violentos acarretou no aumento da agressividade física em meninos, não ocorrendo o mesmo nas meninas, que segundo Bartholow e Anderson se valem de formas indiretas de agressão $^{4}$.

Dessa forma, estudos demonstram que as mídias compõem fatores decisivos na criação da identidade pessoal do indivíduo, bem como o seu comportamento. Sendo que esse pode ser um comportamento agressivo influenciado e até recompensado por jogos, filmes e músicas que fazem parte da rotina dos jovens e das crianças. Ainda assim, apesar da influência dessas mídias na construção do caráter, faltam estudos para mensurar os níveis de ação e as consequências no decorrer da formação pessoal do indivíduo em questão.

\section{Desenvolvimento}

Para melhor compreensão e leitura do referido assunto, o trabalho foi dividido em subtópicos, sendo eles: games, filmes e músicas.

\section{Games}

Quando o assunto se refere a jogos eletrônicos, muito se discute acerca das suas influências nos âmbitos comportamentais e psicológicos nos jogadores. Nesse sentido, ainda há muitas discussões sobre as influências dos games na agressividade, em especial nos jovens, visto que diversas fatalidades dos últimos anos, como o Massacre de Columbine em 1999 ou o recente Atentado de Suzano, no qual os jovens foram, supostamente, influenciados pelos jogos eletrônicos a cometerem a tais atos ${ }^{1}$.

Ainda assim, com tantas discussões sobre tal tema há uma escassez de estudos sobre o caso ${ }^{1}$. Ademais, é inegável que os jogos eletrônicos estimulam características 
como engajamento, sistema de recompensa imediata e aplicação repetitiva de determinadas habilidades. Dessa forma, segundo pesquisas recentes, a interação com os jogos digitais, por estarem bem próximas da realidade e assumirem um carácter quase simulatório, "possibilita que o conhecimento produzido a partir da experiência de jogo influencie a percepção e interpretação de situações de jogo, podendo envolver estados afetivos, estruturas cognitivas e scripts comportamentais que guiarão o comportamento dos jogadores em situações futuras”, o que e conhecido como o modelo GLM ${ }^{1}$.

Segundo dados da literatura, esse método permite o aprendizado e o incorporamento de habilidades desenvolvidas no aprendizado prático. Nesse sentido, os jogos eletrônicos poderiam influenciar os jovens no sentido que, ao simularem uma realidade, eles poderiam incorporar novos traços a personalidade dos jogadores. Assim, segundo esse método, o quão mais imersivo for o game, mais influente ele é na vida do indivíduo. Dessa maneira, como os games possuem um papel ativo, já que o jogador controla a animação dentro da tela, e como alguns jogos te recompensam por tomar atitudes violentas, o jogador, aos poucos, incorporaria a correlação entre ter hábitos agressivos com uma recompensa. Mais do que isso, os jogos violentos, se comparados aos jogos neutros, tenderiam a aumentar a ocorrência de afetos negativos e diminuir os positivos ${ }^{1}$.

Porém, esses métodos são questionados, já que as pesquisas sofrem acusações de serem enviesadas e carregadas de preconceitos que atrapalham o rumo das pesquisas. Visto que todas essas pesquisas foram conduzidas com games disponíveis no mercado e não um produzido com fins de pesquisa, os resultados possuem "lacunas, como a dificuldade na replicação de efeitos relevantes e da importância de outras variáveis" ${ }^{1}$.

Nesse sentido, outros dados da literatura contradizem a correlação de games e agressividade. Segundo pesquisas de Andrew K. Przybylski e Netta Weinstein, um estudo conduzido com 1000 adolescentes do Reino Unido, não permitiu associar o hábito de jogar jogos eletrônicos de caráter violento com o desenvolvimento de comportamentos agressivos. Por se tratar de uma pesquisa com um caráter mais subjetivos, os pesquisadores foram na contramão de outras pesquisas, eliminando certos preconceitos existentes em perguntas feitas aos participantes em testes passados. No lugar, os pesquisadores procuraram questioná-los sobre fatos mais objetivos, eliminando respostas tendenciosas e flexíveis ${ }^{3}$. 
Assim, ambos os trabalhos aqui analisados questionam a metodologia aplicada nas pesquisas que buscam correlacionar o hábito de jogar vídeo games violentos com o desenvolvimento de uma personalidade agressiva. Dessa maneira, ambos consideram as pesquisas inconclusivas, já que os resultados presentes em diversas pesquisas são divergentes.

\section{Músicas}

Numa comparação de atividades de lazer, verificou-se que ouvir música era a atividade mais frequente do que assistir televisão, ler livros e assistir a filmes ${ }^{5}$ A música tem uma participação importante em facilitar que as pessoas se conheçam e se atraiam umas pelas outras, criando cenários para os relacionamentos humanos, além de ajudar a definir a identidade pessoal e social. Pois as letras retratam o dia-a-dia de um determinado grupo, sendo então consumida por indivíduos que se identificam com a música. Influenciando na forma de falar, no vestuário e até atração ou repulsão por determinados grupos sociais $^{2}$.

Verificou-se que a música interfere tanto em comportamentos antissociais, cujo comportamentos de agressão, violência e quebra de normas sociais definem esse aspecto, quanto no comportamento pró-social, o qual é resumido em comportamentos de ajuda, cordialidade e altruísmo. Porém fora constatado que, principalmente em músicas de rock e rap, "o aspecto pró-social da música popular tem sido amplamente ignorado" ${ }^{2}$. Existem relatos de crimes ocorridos, supostamente, sob a influência de músicas exageradamente melancólicas, perturbadoras, com letras agressivas e temas psicodélicos, de bandas de rock e heavy metal. Outros por seu turno têm destacado a ligação de astros do rap com atividade criminal, incluindo participação em gangs, disputas e brigas entre artistas. Estudiosos apontam a relação da preferência de jovens por músicas cujo tema se baseia em antipatriotismo, antissemitismo, homofobia, sentimentos de alienação, anonimato e depressão.

As pressões sociais que cada indivíduo sofre são diferentes, além da forma como ele lida com essas pressões, gerando a sua identidade. Os estilos musicais escutados também não são apenas de um ritmo, como Ballard et al. (1999) encontrou em sua pesquisa com estudantes de psicologia próximos de 18 anos que a maioria não escuta apenas um gênero musical, e muitos não tinham um gênero preferido ${ }^{5}$. Em seu estudo fizeram mensurações fisiológicas aferindo pressão sanguínea e encontraram correlações 
positivas entre níveis de excitação fisiológica (arousal), músicas como heavy metal e RAP, e busca por sensações e comportamentos antissociais em homens. Também buscaram correlacionar preferência musical e comportamento imprudente (ou arriscado), em seu estudo demonstrou relação direta entre preferência por heavy metal e comportamentos de alto risco, como dirigir intoxicado, dirigir em alta velocidade, uso de drogas, promiscuidade sexual e vandalismo.

Em suma, na análise dos artigos encontrados, a música tem importante papel social e psicológico no indivíduo, a percepção das letras de tais músicas é uma área que merece ainda muitos estudos em uma perspectiva psicossocial.

\section{Filmes}

As crianças e os jovens brasileiros, já em 1998, gastavam em média 3h57min por dia assistindo televisão ${ }^{4}$. Alguns pais julgam a influência das mídias televisivas como um "mal necessário" que tanto atrapalha quanto ajuda, e outros como algo prejudicial, que é conflitante com alguns valores familiares. As justificativas que dizem respeito às avaliações negativas foram as seguintes:

- A programação considerada inadequada, veiculando sem critérios, temas polêmicos, como sexo e drogas, e distorcendo de certa forma a realidade ${ }^{4}$;

- Antecipação de temas e problemas, como homossexualismo, traição, suborno, violência, drogas e prostituição, reduzindo de certa forma o período de inocência das crianças, o que pode gerar problemas comportamentais futuros ${ }^{4}$;

- Usurpação do tempo de convívio familiar ${ }^{4}$.

Pesquisas relacionadas ao índice de cenas de violência em desenhos animados classificados como abertos à audiência geral, que continham pelo menos um ato de violência e mostravam ferimentos, incluindo os fatais em $62 \%$ dos filmes, entre eles estavam os filmes: O Rei Leão e Toy Story ${ }^{4}$.

Nas décadas de 20 e de 90, permitem observar a mudança de visão das crianças no que diz respeito aos modelos que elas consideram atrativos. Nas décadas de 20 a 40, "a família era apontada pelas crianças como a grande agência fornecedoras de modelos, seguida pela escola, e pela igreja, na pessoa de Deus, Jesus e Santos". "Na década de 90, as crianças consideravam como modelos de identificação, em primeiro lugar, artistas de televisão, cantores, atletas, pessoas que elas tinham contato por meio da mídia. Tendência essa registrada tanto para as meninas $(47 \%)$ quanto para os meninos $(37,2 \%)$ " 4 . 
Um experimento realizado por Gomide (2000) descreve uma pesquisa que avaliava os efeitos de filmes com cenas de violência sobre o comportamento agressivo de crianças, neste experimento, a autora concluiu que no sexo masculino, os filmes com cenas de violência, aumentaram o comportamento agressivo, o que não ocorreu com o sexo feminino. Gomide sugere que o comportamento agressivo de meninas também é afetado quando relacionado a cenas de violência que envolvem abuso psicológico e/ou sexual contra mulheres ${ }^{4}$.

Uma pesquisa realizada, refere-se ao aumento da agressividade de crianças entre 9 e 12 anos de idade em estórias redigidas antes e depois de assistirem ao filme Mortal Kombat. Os resultados foram similares ao experimento conduzido por Gomide, quanto ao comportamento diferenciado de meninos e de meninas, apesar de em algumas redações ambos os sexos terem aumentado o nível de agressividade ${ }^{4}$.

Alguns estudos, como o de Bjorkqvist e cols. podem explicar essas diferenças relacionadas ao gênero dos participantes. Esses estudiosos demonstram que "adolescentes do sexo masculino são mais propensos a passar rasteira, chutar ou xingar, enquanto adolescentes do sexo feminino, mas frequentemente ignoram ou substituem o provocador por um rival" 4.

Diferenças relacionadas a agressões verbais entre os gêneros, são melhores explicadas por Bartholow e Anderson na seguinte afirmação: "Em outras palavras, homens provavelmente empregam, com maior frequência, formas diretas de agressão, enquanto mulheres usam de formas indiretas - ações que são prejudiciais para os outros de maneiras mais sutis" 4.

Foram desenvolvidas diversas teorias com bases em estudos, dentre elas estão a teoria Neo-cognitiva de Bushman que diz que o efeito da mídia é mais efetivo em indivíduos que já possuem tendência agressiva, por possuírem ampla rede de associações agressivas, que pode ser ativada por estímulos violentos. E a teoria Neo-associativa da Agressão de Berkowitz que diz que exposição à violência é responsável por ativar processos cognitivos que influenciam atitudes agressivas 4 .

Baseado nessas e outras teorias propostas, desenvolveu-se um Modelo Geral de Agressão, que propõe que o comportamento agressivo é desempenhado com base em conhecimentos desses comportamentos armazenados na memória ${ }^{4}$.

As respostas agressivas de crianças e adolescentes, podem estar baseadas também em fatores biológicos (genéticos), comportamentais e culturais ${ }^{4}$. 
Não há consenso a respeito de uma explicação mais adequada para o fato de seres humanos se comportarem de maneira agressiva, porém, existe um segmento social que lucra e se beneficia com o uso da violência na mídia, sem se preocupar com os efeitos que isso pode ter na sociedade em geral ${ }^{4}$.

Outro estudo tenta compreender o fenômeno da agressão em seus múltiplos e diversos aspectos e nuances usando o filme "Sob o domínio do medo" para exemplificar e detalhar as ideias apresentadas etiológica e antropologicamente ${ }^{6}$.

Primeiramente, a violência física ou psicológica é composta por uma série de vetores secundários que garantem a esse fenômeno seu caráter multifacetário que envolve variados tipos de comportamento. Estes, por sua vez, encontram-se atrelados a diferentes e específicas funções adaptativas que, no reino animal, podem ser de natureza territorial, sexual, predatória e assim por diante ${ }^{6}$.

Segundo o autor, há um improvável favorecimento evolutivo da agressão em particular, já que haveria outras formas utilizadas pelos animais como medidas de sobrevivência. No caso do homem, tem-se ainda a própria utilização da linguagem e dos valores morais como mediadores de conflitos. Dessa maneira, a agressão não se configura nem como o único e nem como o melhor caminho evolutivo. Não sendo necessariamente boa ou má, deteria sim um caráter situacional, respondendo de maneira adaptativa à mutabilidade do meio ambiente ${ }^{6}$.

A partir desse princípio, o questionamento do porquê o homem, entre todas as espécies, ser o único a realizar matanças em massa necessita de uma ponderação prévia: a agressão dificilmente ocorre em uma forma pura, mas sim, como parte de um sistema adaptativo mais amplo. Fatores como a explosão populacional, associada, por sua vez, aos avanços da agricultura e da medicina provocaram o sentimento de não ter lugar na própria sociedade. Essa sensação de não pertencimento conduziria ao problema da guerra e da matança em larga escala. Estas também relacionadas a avanços culturais, como o desenvolvimento das telecomunicações e de poderosos armamentos que, funcionando à longa distância, vetariam ao atacado a possibilidade de enviar sinais apaziguadores diante da fúria de seu oponente ${ }^{6}$.

Há, ainda, teorias que relacionam esse quadro com o discurso cambista com base na teoria sociológica de Lévi-Strauss. As relações estabelecidas entre sociedades teriam caráter puramente comercial e, nesse caso, a figura do guerreiro seria desassociada da glória de batalhar e ressignificada como uma concepção primitiva como meio para um 
fim político apenas. As sociedades, na sua essência e vontade sociológica, estariam associadas à fragmentação ${ }^{6}$.

Partindo para a etnografia do filme "sob o domínio do medo", falas como a do personagem Tom quando indagado pelo major Scott após quebrar um copo e ferir a mão de um funcionário do bar no qual estava - "sou o que sou" - revelam uma influência da visão que a violência é algo intrínseco ao humano, é de sua natureza ${ }^{6}$.

Outras cenas fazem, ainda, um paralelo entre o racional e irracional nas discussões apresentadas no filme. Quando mais acalorada a discussão, mais irracionalmente o personagem se caracteriza. Essas cenas podem sugestionar a seus interlocutores - os espectadores- que a violência é algo irracional e, de certa forma, é aceitável em momentos que a racionalidade se perde ${ }^{6}$.

Pode-se ainda citar que, de forma geral, os moradores da cidade rural para a qual os personagens principais viajam são caracterizados como "inferiores" no sentido de mostrarem o paralelo criado pela atmosfera do filme de que o campo é o lugar irracional, um lugar violento, que "faz justiça com as próprias mãos"; enquanto a cidade é o lugar da racionalidade, da civilização ${ }^{6}$.

Por conseguinte, a violência, apesar de ser multifatorial e apresentar-se como um conceito plural sobre o qual interpretações também plurais são possíveis, o cinema quase sempre a caracteriza e influência os espectadores a entendê-la de dois modos: como algo intrínseco à cultura e natureza humana ou como algo longe do racional, como é o caso do filme "Sob o domínio do medo", longe do homem moderno e de seus hábitos. Há, portanto, uma concomitância entre as visões antropológicas e etnográficas das interpretações da violência.

\section{Conclusão}

Tendo em vista a importância e atualidade da discussão das múltiplas facetas da agressividade e da influência que mídias de entretenimento têm sobre o tema, verificouse após a presente revisão bibliográfica que os resultados necessitam de mais estudos para que se possa dar um veredito definitivo acerca dessa relação.

Apesar disso, pode-se notar que jogos eletrônicos, música e cinema exercem significativa interferência no comportamento de seus interlocutores, na medida que fomenta indiretamente um comportamento de atitudes agressivas. 
Sendo assim, essas mídias alteram o comportamento pró-social, na medida que eleva a realidade virtual para mais próximo do interlocutor e ativa áreas cerebrais que estão associadas ao prazer e recompensa, que pode fazê-lo imitar tais atos no mundo real, já que ele encontra nessas mídias bases de apoio para isso.

\section{Referencias}

1. SARMET, Mauricio; PILATI, Ronaldo. Efeito dos jogos digitais no comportamento: análise do General Learning Model. Temas em Psicologia - 2016, Vol. 24, n 1, 17-31

2. PIMENTEL, Carlos; GÜNTHER, Hartmut. Percepção de letras de músicas como inspiradoras de comportamentos antissociais e pró-sociais. Psico, Porto Alegre, PUCRS, v. 40, n. 3, pp. 373-381, jul./set. 2009

3. PRZYBYLSKI, Andrew K.; WEINSTEIN, Netta. Violent video game engagement is not associated with adolescents' aggressive behaviour: evidence from a registered report. R. Soc. open sci, 2019.

4. BATISTA, Ana; FUKAHORI, Lídia; HAYDU, Verônica. Filme com cenas de violência: efeito sobre o comportamento agressivo de crianças expresso no enredo de uma redação. Interação em Psicologia, jan./jun. 2004, (8)1, p. 89-102.

5. PIMENTEL, Carlos; GOUVEIA, Valdiney; VASCONCELOS, Tatiana. Preferência musical, atitudes e comportamentos anti-sociais entre estudantes adolescentes: um estudo correlacional. Estudos de Psicologia I Campinas I 22(4) I 403-413 I outubro - dezembro 2005.

6. DE SOUZA, Mauricio. Etologia, Antropologia e cinema: uma etnografia da violência em Sob o Domínio do Medo. Psicologia USP, São Paulo, outubro/dezembro, 2009, 20(4), 619-637. 